\title{
A LAMP Protocol for the Detection of 'Candidatus Phytoplasma pyri', the Causal Agent of Pear Decline
}

\author{
A. Siemonsmeier, ${ }^{1}$ J. Hadersdorfer, ${ }^{1}$ M. Neumüller, ${ }^{2}$ W. Schwab,${ }^{3, \dagger}$ and D. Treutter ${ }^{1}$ \\ ${ }^{1}$ Associate Professorship of Fruit Science, Technical University of Munich, Dürnast 2, 85354 Freising, Germany ${ }^{2}$ Bavarian Fruit \\ Center, Am Süßbach 1, 85399 Hallbergmoos, Germany ${ }^{3}$ Biotechnology of Natural Products, Technical University of Munich, \\ Liesel-Beckmann-Str. 1, 85354 Freising, Germany
}

\begin{abstract}
Phytoplasmas are cell-wall-less bacteria that cause diseases in approximately 1,000 plant species. 'Candidatus Phytoplasma pyri', the causal agent of pear decline, induces various symptoms on its hosts, leading to weakening and dieback of the plants, reduced fruit size and yield, and, consequently, considerable financial losses in all pear-growing areas. Fighting this disease requires a reliable and inexpensive method for pathogen detection in propagation material as well as plant stocks in orchards and breeding facilities. Here, we present a field-suitable detection protocol for ' $\mathrm{Ca}$. $\mathrm{P}$. pyri' based on loop-mediated isothermal amplification (LAMP) targeting the phytoplasmal 16S ribosomal
\end{abstract}

Abstract
DNA sequence. The combination of a simplified sample preparation method based on sodium hydroxide and colorimetric visualization of LAMP results enables a laboratory-independent pathogen detection. The detection limit is comparable with analysis by polymerase chain reaction; however, the pear decline LAMP detection method is superior in terms of ease of use, cost, and time effectiveness for obtaining results.

Keywords: 'Candidatus Phytoplasma pyri', loop-mediated isothermal amplification, pear decline.
Phytoplasmas are cell-wall-less bacteria belonging to the class of mollicutes (IRPCM 2004). They inhabit the phloem of their host plants and cause diseases in approximately 1,000 plant species (Seemüller and Schneider 2004). Despite a comparatively small genome, phytoplasmas are adapted to organisms of two kingdoms, Plantae and Animalia, because they need an insect vector to be transmitted to their hosts. The taxonomic group 16SrX, defined based on sequence information of the $16 \mathrm{~S}$ ribosomal RNA (rRNA) gene, comprises phytoplasmas that infect temperate fruit trees: 'Candidatus Phytoplasma mali' (apple proliferation [AP]), ' $\mathrm{Ca}$. P. prunorum' (European stone fruit yellows [ESFY]), and ' $\mathrm{Ca}$. P. pyri' (pear decline $[\mathrm{PD}]$ ). Despite being very closely related, these phytoplasmas are, in fact, different species (Seemüller and Schneider 2004). However, with 98.6 to $99.1 \%$ sequence similarity, the $16 \mathrm{~S}$ rDNA sequence is highly conserved among members of this group. The causal agent of $\mathrm{PD}$, ' $\mathrm{Ca}$. P. pyri', can induce various symptoms on its host plants; for example, wilt, premature reddening and drop of leaves, stunting, and reduced size of fruit (Seemüller et al. 2011). Symptom severity and disease development are dependent on the variety and the rootstock-scion combination. However, there is no early specific symptom associated with $\mathrm{PD}$, which makes a reliable

Current address of A. Siemonsmeier: Bavarian State Institute of Forestry, Department Biodiversity, Conservation and Hunting, Hans-Carl-von-CarlowitzPlatz 1, 85354 Freising, Germany

${ }^{\dagger}$ Corresponding author: W. Schwab; E-mail: Wilfried.Schwab@tum.de

Funding: This research was funded by the German Federal Office for Agriculture and Food (Bonn, Germany).

D. Treutter died 7 May 2016.

*The $\boldsymbol{e}$-Xtra logo stands for "electronic extra" and indicates that three supplementary figures and three supplementary tables are published online.

The author(s) declare no conflict of interest.

Accepted for publication 28 January 2019.

(c) 2019 The American Phytopathological Society identification of diseased trees by visual inspection very difficult (Seemüller et al. 2011). The PD phytoplasma is transmitted by phloem-sucking insects belonging to the family of Psyllids (Psyllidae) and by grafting infested scions onto healthy plants (Seemüller et al. 2011). Control of the pathogen is achieved by spraying pesticides against the psyllid vectors (Seemüller et al. 2011). Furthermore, phytosanitary measures such as clearing of infested trees and use of certified, disease-free propagation material are recommended (Seemüller et al. 2011). Continuous control of plant stocks and propagation material as well as selection of resistant or tolerant pear cultivars within breeding programs are of primary importance in the fight against this quarantine disease. A prerequisite for this purpose is a pathogen detection method suitable for high-throughput screenings, and which is ideally feasible on site by the fruit growers themselves. Here, costs and complexity of the method are critical factors.

Conventional detection methods for the PD phytoplasma are polymerase chain reaction (PCR), nested PCR, and real-time PCR protocols, using group-specific or species-specific primers mainly targeting the $16 \mathrm{~S}$ and $23 \mathrm{~S}$ ribosomal DNA (rDNA) sequences or the 16S-23S rDNA spacer region (Deng and Hiruki 1991; Lorenz et al. 1995; Torres et al. 2005). These widely established methods require a well-equipped laboratory and experienced personnel. In contrast, the development of isothermal DNA amplification techniques during the past three decades enables the detection of pathogens without the need of thermal cyclers; for example, helicasedependent amplification (HDA) (Vincent et al. 2004), loopmediated isothermal amplification (LAMP) (Notomi et al. 2000), nucleic acid sequence-based amplification (Compton 1991), and rolling circle amplification (Fire and Xu 1995). LAMP uses a DNA polymerase with strand displacement activity and a set of four or six specially designed primers to enable a temperature-independent autocycling during amplification (Notomi et al. 2000). This technique works at a constant temperature of 60 to $65^{\circ} \mathrm{C}$, offering the possibility to perform the reactions in a heat block or a water bath. Bst DNA polymerase, commonly used in LAMP, is highly tolerant against inhibitory substances (Kaneko et al. 2007), enabling the use of "quick-and-dirty" protocols for sample preparation. This makes the LAMP method suitable for laboratory-independent testing procedures, because it requires only a simple heating block and crude sample preparations (Hadersdorfer et al. 2011; Mori et al. 2013; Sugawara et al. 2012). A range of sample preparation methods are 
reported in combination with LAMP assays, from water-based homogenization of leaf tissues (Hadersdorfer et al. 2011) to lateralflow-device extractions (Tomlinson et al. 2010) to simplified alkaline solution-based procedures (Sugawara et al. 2012). Furthermore, various techniques for the visualization of the results are possible with LAMP. Apart from agarose gel electrophoresis of ethidium bromide-stained amplification products (Notomi et al. 2000), several methods for the indirect detection of DNA amplification in LAMP have been proposed. The formation of high amounts of the amplification byproduct magnesium pyrophosphate leads to an increasing turbidity of the reaction solution, which can be recognized by the naked eye (Mori et al. 2001). Centrifugation of the reaction tubes results in the formation of whitish pellets (Hadersdorfer et al. 2011; Mori et al. 2001). Commercially available turbidimeters measure the turbidity of the reaction solution and give qualitative as well as quantitative results (Mori et al. 2013). Direct detection of amplification products can be achieved with DNA-intercalating fluorescence dyes such as SYBR Green I (Soli et al. 2013) or V13 (Denschlag et al. 2013), and Optigene provides the portable device Genie II for LAMP reactions using fluorescence chemistry for the detection of LAMP products. Other approaches employ the metal indicator dyes hydroxy naphthol blue (HNB) (Goto et al. 2009) or calcein, which indicate the complexation of magnesium ions and, thus, the amount of pyrophosphate anions by a color change. In this study, colorimetric detection of LAMP results with HNB should have been performed to provide a field-suitable pathogen detection assay. However, HNB appeared to be unstable during the development process of PD LAMP, as shown by different intensities and hues of the color in different replicates of the same experiments and a poor contrast between positive and negative samples. The search for an alternative metal indicator dye yielded the most promising results for Eriochromeblack-T (ErioT), an azo dye mainly used in complexometric titrations; for example, the determination of water hardness with EDTA (Betz and Noll 1950; Biedermann and Schwarzenbach 1948). At a pH between 7 and 11 , the dye is in its blue form in the absence of metal ions and turns to a bright purple when it forms a complex with magnesium (Skoog et al. 2014). Until now, the use of ErioT in LAMP reactions was only rarely reported; however, Shigemoto et al. (2010), Oh et al. (2016), and Rodriguez-Manzano et al. (2016) demonstrated the suitability of ErioT for colorimetric detection in LAMP assays.

The potential of LAMP is high, especially for point-of-care diagnostics of infectious diseases in resource-limited settings (Mori et al. 2013). The phytoplasma research community has also discovered LAMP as a promising alternative to conventional detection methods such as PCR and real-time PCR (De Jonghe et al. 2017; Obura et al. 2011; Sugawara et al. 2012; Tomlinson et al. 2010). However, most of these approaches still rely on the availability of a well-equipped laboratory and skilled personnel because they were developed for use with either complex detection systems or conventional DNA extraction procedures.

Here, we report the development of a simplified sample preparation procedure and a LAMP protocol for the detection of ' $\mathrm{Ca}$. P. pyri' that works without expensive equipment, is easy to perform by inexperienced users, and is laboratory-independent. There is no need for a thermal cycler or gel electrophoresis. The reaction is carried out in a heating block or water bath and the results can simply be judged by the naked eye.

\section{Materials and Methods}

Sources of phytoplasma DNA. DNA of phytoplasmas belonging to the AP group was extracted from phytoplasma-infected plants. PD-positive controls used in LAMP and PCR as well as for the dilution series in the LAMP optimization experiments derived from an in vitro culture of pear plants infested with the PD phytoplasma, which were kindly provided by Dr. Bernd Schneider (Julius-Kühn-Institut [JKI]). Phytoplasma-free negative controls derived from an in vitro culture of healthy Williams pear fruit. Plants from these in vitro cultures were also used for the evaluation of the simplified sample preparation procedure (information regarding the culture conditions for the in vitro plants is given in Supplementary Table S1). DNA of all other phytoplasmas was kindly provided by Prof. Assunta Bertaccini (University of Bologna, Italy). The pGemT plasmid containing the P1/P7 fragment of the $16 \mathrm{~S}$ rDNA sequence of ' $\mathrm{Ca}$. P. pyri' as insert was kindly supplied by Dr. Bernd Schneider (JKI). A summary of the phytoplasma strains used in this study is given in Table 1.

Conventional DNA extraction. Plant tissues intended for conventional DNA extraction were frozen in liquid nitrogen and ground by hand with precooled screwdrivers in 15-ml falcon tubes. Extraction of DNA from phytoplasma-infected and phytoplasma-free plant tissues was performed with the DNeasy Plant Mini Kit (Qiagen) according to the manufacturer's instructions. DNA was eluted in a volume of $200 \mu \mathrm{l}$ of elution buffer.

Simplified sample preparation. The simplified sample preparation method with sodium hydroxide $(\mathrm{NaOH})$ for use in LAMP and direct PCR is a modified version of the fast plant extraction procedure published by Hadersdorfer et al. (2011), which uses water for homogenization of leaf tissues. Samples from different plant organs were treated separately. Midveins and petioles of leaves were cut out with a sterilized razor blade. Shoots and roots were decorticated to obtain bark and phloem tissue. Fine roots were used as they were. Whole in vitro plants were used without the callus. A maximum of $1 \mathrm{~g}$ of fresh plant material was weighed into a filter extraction bag (extraction bag Universal; Bioreba) containing $10 \mathrm{ml}$ of either $0.5 \mathrm{M} \mathrm{NaOH}$ for leaves and in vitro plants or $0.1 \mathrm{M} \mathrm{NaOH}$ for bark of shoots and roots $(1 \mathrm{ml}$ of $\mathrm{NaOH}$ solution per $100 \mathrm{mg}$ of fresh plant tissue). The material was ground with a Homex-6 homogenizer (Bioreba). Approximately $1.8 \mathrm{ml}$ of the resulting homogenate was transferred to a 2-ml reaction tube and centrifuged for $5 \mathrm{~min}$ at $10,000 \times \mathrm{g}$. The supernatant was diluted 1:100 with distilled water and $2 \mu \mathrm{l}$ of this dilution was added directly to the LAMP reaction mix. direct PCR were performed with $1 \mu \mathrm{l}$ of the diluted supernatant.

LAMP reaction. Six LAMP primers-forward inner primer (FIP), backward inner primer (BIP), outer primers F3 and B3, loop forward primer (LF), and loop backward primer (LB)-were

Table 1. Phytoplasma strains used in this study

\begin{tabular}{|c|c|c|c|}
\hline Phytoplasma & Disease & Classification & 16Sr-Group ${ }^{\mathrm{a}}$ \\
\hline $\mathrm{AP}$ & Apple proliferation & 'Candidatus Phytoplasma mali' & $\mathrm{X}-\mathrm{A}$ \\
\hline ASHY & Ash yellows & 'Ca. P. fraxini' & VII-A \\
\hline AY & Aster yellows & 'Ca. P. asteris' & $\mathrm{I}-\mathrm{A}$ \\
\hline AY-A & Apricot chlorotic leafroll & 'Ca. P. asteris' & $\mathrm{I}-\mathrm{F}$ \\
\hline BVK & Flower stunting & 'Ca. P. oryzae' & $\mathrm{XI}-\mathrm{C}$ \\
\hline $\mathrm{CH}-1$ & Grapevine yellows & 'Ca. P. solani' & XII-A \\
\hline $\mathrm{CX}$ & Peach $\mathrm{X}$ disease & 'Ca. P. pruni' & III-A \\
\hline ELM WB & Elm witches' broom & 'Ca. P. ulmi' & V-A \\
\hline ESFY & European stone fruit yellows & 'Ca.P. prunorum' & $\mathrm{X}-\mathrm{B}$ \\
\hline PD & Pear decline & 'Ca. P. pyri' & $\mathrm{X}-\mathrm{C}$ \\
\hline PWB & Potato witches' broom & 'Ca. P. trifolii' & VI-A \\
\hline TBB & Tomato big bud & 'Ca. P. aurantifolia' & II-A \\
\hline
\end{tabular}

${ }^{\mathrm{a}}$ Based on Lee et al. (1995). 
designed using the software LAMP Designer (Premier Biosoft International), based on the 16S rDNA sequence of the PD phytoplasma (GenBank accession number AJ542543.1). Primer sequences are given in Table 2. Consensus of the primer sequences with the target sequences of the PD phytoplasma strains available in the GenBank database as well as possible cross-reactivity with common pear pathogens was investigated with a BLASTn analysis (https://blast.ncbi. nlm.nih.gov/Blast.cgi?PAGE_TYPE=BlastSearch). Primers were synthesized by Eurofins MWG. The LAMP reaction mix contained outer primers (F3 and B3) at $0.2 \mu \mathrm{M}$ each, inner primers (FIP and $\mathrm{BIP}$ ) at $1.6 \mu \mathrm{M}$ each, loop primers (LF and LB) at $0.8 \mu \mathrm{M}$ each, $20 \mathrm{mM}$ Tris-HCl (pH 8.8) (AppliChem), $10 \mathrm{mM} \mathrm{KCl}$ (Merck), $10 \mathrm{mM}\left(\mathrm{NH}_{4}\right)_{2} \mathrm{SO}_{4}$ (Merck), 0.1\% Tween-20 (AppliChem), $4.8 \mathrm{mM} \mathrm{MgCl}_{2}$ (Merck), either $4 \mu \mathrm{l}$ of $30 \%$ (wt/vol) polyethylene glycol (PEG) 8k (final concentration $=4.8 \%$; Sigma-Aldrich) or $1 \mathrm{M}$ betaine (Sigma-Aldrich), $120 \mu \mathrm{M}$ ErioT (Merck), $0.8 \mathrm{mM}$ each dNTP (New England Biolabs), 8 U of Bst DNA polymerase large fragment (New England Biolabs), and $2 \mu$ l of DNA extract or diluted homogenate in a total volume of $25 \mu \mathrm{l}$. For the determination of the optimal magnesium ion concentration, $\mathrm{MgCl}_{2}$ concentrations were varied from 4 to $6 \mathrm{mM}$ per reaction in $0.4-\mathrm{mM}$ steps. The optimal concentration of PEG $8 \mathrm{k}$ was determined in a concentration series of 2.4 to $7.2 \%$ PEG $8 \mathrm{k}$ per reaction in $1.2 \%$ steps. Experiments with the metal indicator HNB contained $120 \mu \mathrm{M}$ dye per reaction instead of ErioT. LAMP reactions were incubated for $60 \mathrm{~min}$ at $65^{\circ} \mathrm{C}$ in a heat block. Results were determined by visual inspection of the color of the LAMP reaction solutions. Successful amplification from samples containing pathogen DNA led to a color change of the metal indicator dye from purple to blue. The results were confirmed by agarose gel electrophoresis of LAMP products on $2 \%$ agarose gels stained with ethidium bromide.

Conventional PCR. Conventional PCR was performed with the primer pair fO1/rO1, which specifically detects fruit tree phytoplasmas of the 16SrX group (Lorenz et al. 1995). PCR primers were synthesized by Eurofins MWG. The PCR contained primers fO1 and rO1 at $0.5 \mu \mathrm{M}$ each, $2.5 \mu \mathrm{l}$ of $10 \times$ PCR buffer (Fermentas), $1.5 \mathrm{mM} \mathrm{MgCl}_{2}$ (Fermentas), $0.1 \mathrm{mM}$ each dNTP (New England Biolabs), $1 \mathrm{U}$ of Taq DNA polymerase (Fermentas), and $2 \mu \mathrm{l}$ of DNA in a total volume of $25 \mu \mathrm{l}$. Thermal cycling conditions were $1 \mathrm{~min}$ at $95^{\circ} \mathrm{C}, 1 \mathrm{~min}$ at $52^{\circ} \mathrm{C}$, and $1 \mathrm{~min}$ at $70^{\circ} \mathrm{C}$ for 35 cycles, with an initial denaturation step of $5 \mathrm{~min}$ at $95^{\circ} \mathrm{C}$ and a final elongation step of $5 \mathrm{~min}$ at $70^{\circ} \mathrm{C}$. Amplification products were visualized by agarose gel electrophoresis on a $1 \%$ agarose gel stained with ethidium bromide. For the estimation of PCR fragment sizes, the size marker GeneRuler 1-kb plus DNA Ladder (Fermentas) was used.

Direct PCR. Direct PCR of samples prepared with the simplified plant-tissue preparation procedure was performed using primer pair fO1/rO1 (synthesized by Eurofins MWG) (Lorenz et al. 1995) and the Phire Plant Direct PCR Kit (Thermo Scientific) according to the manufacturer's instructions. The direct PCR contained primers fO1 and rO1 at $0.5 \mu \mathrm{M}$ each, $10 \mu \mathrm{l}$ of $2 \times$ Phire Plant PCR buffer, $0.4 \mu \mathrm{l}$ of Phire Hot Start II DNA polymerase, and $1 \mu \mathrm{l}$ of sample in a total volume of $20 \mu \mathrm{l}$. Thermal cycling conditions were $5 \mathrm{~s}$ at $98^{\circ} \mathrm{C}, 5 \mathrm{~s}$ at $52^{\circ} \mathrm{C}$, and $20 \mathrm{~s}$ at $72^{\circ} \mathrm{C}$ for 40 cycles, with an initial denaturation step of $5 \mathrm{~min}$ at $98^{\circ} \mathrm{C}$ and a final elongation step of $1 \mathrm{~min}$ at $72^{\circ} \mathrm{C}$. Amplification products were visualized by agarose gel electrophoresis on a $1 \%$ agarose gel stained with ethidium bromide.

Real-time PCR. Real-time PCR with the DNA intercalating dye SYBR Green I (Sigma-Aldrich) was performed according to Torres et al. (2005). The applied primer pair P1 (Deng and Hiruki 1991) and R16(x)F1r (Torres et al. 2005) specifically detects phytoplasmas belonging to the taxonomic group 16SrX. Real-time PCR mix $(25 \mu \mathrm{l})$ contained $1 \times$ iQ SYBR Green Supermix (Bio-Rad), $0.2 \mu \mathrm{M}$ primer $\mathrm{P} 1,0.2 \mu \mathrm{M}$ primer R16(x)F1r, and $3 \mu \mathrm{l}$ of sample. Controls and samples were run in triplicate. Reactions were incubated for $10 \mathrm{~min}$ at $95^{\circ} \mathrm{C}$ and then subjected to 40 cycles composed of $95^{\circ} \mathrm{C}$ for $15 \mathrm{~s}$, $60^{\circ} \mathrm{C}$ for $30 \mathrm{~s}$, and $72^{\circ} \mathrm{C}$ for $30 \mathrm{~s}$. Finally, the PCR were heated from 60 to $95^{\circ} \mathrm{C}$ in $0.5^{\circ} \mathrm{C}$ steps to perform a melting curve analysis. Realtime PCR were performed with the MiniOpticon Real-Time PCR System (Bio-Rad). Analysis of real-time PCR experiments was carried out with the software CFX Manager 3.1 (Bio-Rad). The detection limit of the PD LAMP assay in comparison with real-time PCR according to Torres et al. (2005) as well as conventional PCR with the primer pair fO1/rO1 was estimated by means of a 10-fold dilution series of a pGemT plasmid with P1/P7 insert, which comprises a 1,785-bp DNA fragment of the 16S rRNA gene, 16S/23S rDNA spacer region, tRNA-Ile, and partial 23S rRNA gene of the $\mathrm{PD}$ phytoplasma. The tested copy numbers ranged from $10^{\circ}$ to $10^{8}$ copies/reaction. Each run included no-template controls, which contained ultrapure water instead of DNA, as well as negative controls containing DNA extracts from healthy, uncontaminated pear of an in vitro culture.

\section{Results}

Primer design. The PD primer set of the PD LAMP reaction was designed on the $16 \mathrm{~S}$ rDNA reference sequence of ' $\mathrm{Ca}$. P. pyri' (GenBank accession number AJ 542543.1) and consisted of two outer primers (PD-F3 and PD-B3), two inner primers (PD-FIP and PD-BIP), and two loop primers (PD-LF and PD-LB) (Table 2). A BLASTn analysis was performed to check the primers for possible cross-reactivity with the pear pathogens Gymnosporangium sabinae (pear rust), Venturia pyrina (scab), Stemphylium vesicarium (brown spot disease), Erwinia amylovora (fire blight), and Pseudomonas syringae. Except for one Chinese isolate of $P$. syringae isolated from mulberry, which exhibited $100 \%$ sequence identity of the B2 part of the BIP primer with its $16 \mathrm{~S}$ rRNA gene sequence, only partial sequence identities of the primers with the gene sequences of the investigated pathogens available in the GenBank database were found. The primer BLAST against available DNA sequences of the PD phytoplasma showed a high congruency of the primers with the target. Therefore, no hybridization problems due to intraspecific sequence variation are expected.

Optimization of LAMP reaction conditions. Due to frequently observed fluctuations in color intensity and color change contrast of the dye HNB, the metal indicator ErioT was examined for its suitability in the PD LAMP assay. Because both dyes show similar complexing behaviors, ErioT was applied at the same concentration as is recommended for HNB (Goto et al. 2009). An evaluation of the influence of ErioT on LAMP assay performance showed that the dye had no inhibitory effect on the LAMP reaction (Fig. 1). The LAMP reaction mix with ErioT was optimized in terms of magnesium chloride concentration as well as the applied additive and its corresponding concentration. Optimum concentrations were determined as those yielding the highest sensitivity, as indicated by the color change of the metal indicator dye. The optimal magnesium chloride concentration was determined with a serial dilution of a PD-positive control in duplicate. The highest sensitivity was obtained at a concentration of $4.8 \mathrm{mM}$ magnesium chloride (Fig. 2).

Table 2. Loop-mediated isothermal amplification LAMP primers for the detection of the pear decline (PD) phytoplasma

\begin{tabular}{ll}
\hline Primer & \multicolumn{1}{c}{ Sequence $\left(\mathbf{5}^{\prime} \mathbf{- \mathbf { 3 } ^ { \prime } )}\right.$} \\
\hline PD-F3 & GTCTTAACTGACGCTGAGG \\
PD-B3 & CATGCACCACCTGTATCC \\
PD-FIP (F1c-F2) & ACGTACTACTCAGGCGGAGTACAACGATGAGTACTAAGTGTTGG \\
PD-BIP (B1c-B2) & AATTGACGGGACTCCGCACTGTCAAGACCTGGTAAGGT \\
PD-LF & AATGCGTTAACTTCAGCACTG \\
PD-LB & AAGCGGTGGATCATGTTGT \\
\hline
\end{tabular}


During the optimization process of the PD LAMP detection assay with the metal indicator dye ErioT, the additive PEG 8k was evaluated as an alternative to the more widely used betaine in order to investigate a potential enhancing effect on LAMP sensitivity. In contrast to betaine, which influences DNA melting temperature (Jensen et al. 2010), PEG 8k promotes enzymatic reactions due to a macromolecular crowding effect (Minton 2006). A concentration series of PEG 8k from 2.4 to $7.2 \%$ in $1.2 \%$ steps was tested with a 10-fold dilution series of a PD-positive control. A concentration of $4.8 \%$ PEG $8 \mathrm{k}$ yielded the highest sensitivity, as indicated by the color change of ErioT (Fig. 3).

Detection limit of the PD LAMP assay in comparison with conventional PCR and real-time PCR. The detection limit of the PD LAMP detection assay was estimated with a 10 -fold dilution series of a pGemT plasmid containing the P1-P7 fragment of the ' $\mathrm{Ca}$. P. pyri' $16 \mathrm{~S}$ rDNA sequence and was compared with conventional PCR with primer pair fO1/rO1 (Lorenz et al. 1995) as well as realtime PCR according to Torres et al. (2005). Two additives were investigated for their influence on LAMP sensitivity: betaine and PEG 8k. Concentrations of the target ranged from $10^{8}$ to $10^{\circ}$ copies, except for the LAMP assays with betaine, where the highest copy number was omitted. Experiments were repeated three times. LAMP with $4.8 \%$ PEG $8 \mathrm{k}$ detected $10^{2}$ copies/reaction in two of three experiments (Fig. 4). In the third experiment, the assay detected $10^{3}$ copies but failed to amplify the $10^{2}$ copies. The detection limit of LAMP

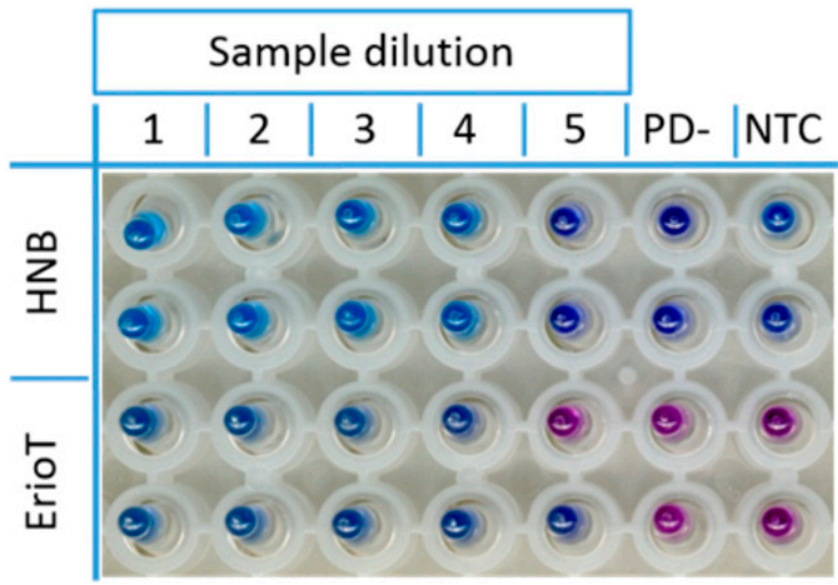

Fig. 1. Loop-mediated isothermal amplification reactions with the metal indicator dyes hydroxy naphthol blue (HNB) and Eriochromeblack-T (ErioT). Lanes 1 to $5=$ dilution series of a pear decline $(P D)$-positive sample (1 = diluted 1:10, $2=1: 100,3=1: 1,000$, $4=1: 10,000$, and $5=1: 100,000)$, PD- $=$ PD-negative control, and NTC $=$ no-template control.

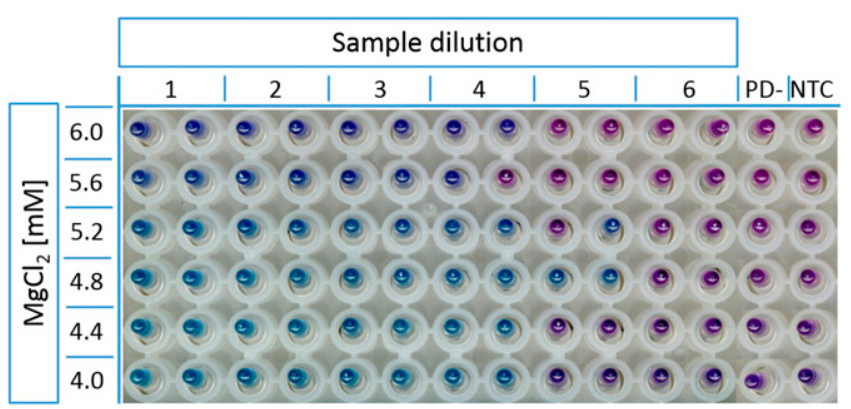

Fig. 2. Pear decline (PD) loop-mediated isothermal amplification analysis applying a magnesium chloride concentration series. Applied concentrations of magnesium chloride $(\mathrm{mM})$ per reaction are given on the left and sample designations at the top. Lanes 1 to $6=$ dilution series of a PD-positive sample $(1=$ diluted 1:10, $2=1: 100$, $3=1: 1,000,4=1: 10,000,5=1: 100,000$, and $6=1: 1,000,000)$, PD- $=$ PDnegative control, and NTC $=$ no-template control. Eriochromeblack-T was used as the metal indicator dye. with $1 \mathrm{M}$ betaine was $10^{4}$ copies in all replications while PCR reached a sensitivity of $10^{2}$ copies/reaction (Fig. 4). Both PCR and LAMP assays failed to amplify the $10^{1}$ and $10^{\circ}$ copies. Real-time PCR according to Torres et al. (2005) was able to detect one copy of the target per reaction. Melt curve analysis confirmed specific amplification in all replicates (Fig. 4). Cycle threshold values and melt temperatures are given in Supplementary Table S2.

With $4.8 \%$ PEG $8 \mathrm{k}$, the color change of positive LAMP reactions correlated well with banding patterns on agarose gels (Fig. 4). Samples below the detection limit yielded no color change; hence, no banding patterns were visible. Although PCR products showed a weakening of intensity on the agarose gel with reduced target concentration, LAMP products were of almost equal intensity at all dilutions. LAMP reactions with $1 \mathrm{M}$ betaine showed a weak color change and a subtle weakening in intensity of the ladder-like banding patterns on the agarose gel in positive reactions. Negative controls containing DNA from healthy plants as well as water controls remained negative in all experiments.

Application of the LAMP assay to a range of phytoplasmas from different phylogenetic groups. Due to the high sequence similarity of the $16 \mathrm{~S}$ rRNA gene among members of the $16 \mathrm{SrX}$ group, the detection of the fruit tree phytoplasmas causing AP and ESFY (Table 1) by the PD LAMP was expected and confirmed in various experiments (Supplementary Figs. S1 and S2). In order to investigate the applicability of the PD LAMP assay to more distantly related phytoplasma strains, both versions of the PD LAMP, with either PEG $8 \mathrm{k}$ or betaine, were tested on DNA samples from a range of phytoplasmas representing different phylogenetic groups. Using betaine, no color change of the reaction mixture and no or very weak unspecific banding patterns on agarose gels were observed for phytoplasmas other than the PD-positive control (Fig. 5). The LAMP assay with PEG 8k successfully amplified all phytoplasma strains tested in this study. A bright color change to blue was visible and ladderlike banding patterns were observed on the agarose gel (Fig. 5). However, subtle differences to the banding pattern derived from the PD-positive control occurred in amplification products from some phytoplasma strains, with several bands missing or new bands being generated.

Evaluation of a simplified extraction method for use in LAMP. Inspired by Wang et al. (1993), who used sodium hydroxide $(\mathrm{NaOH})$ in a quick DNA extraction procedure for Arabidopsis thaliana tissues, the water-based plant tissue homogenization method published by Hadersdorfer et al. (2011) was modified to provide crude preparations of pear leaves and bark for LAMP analysis. In detail,

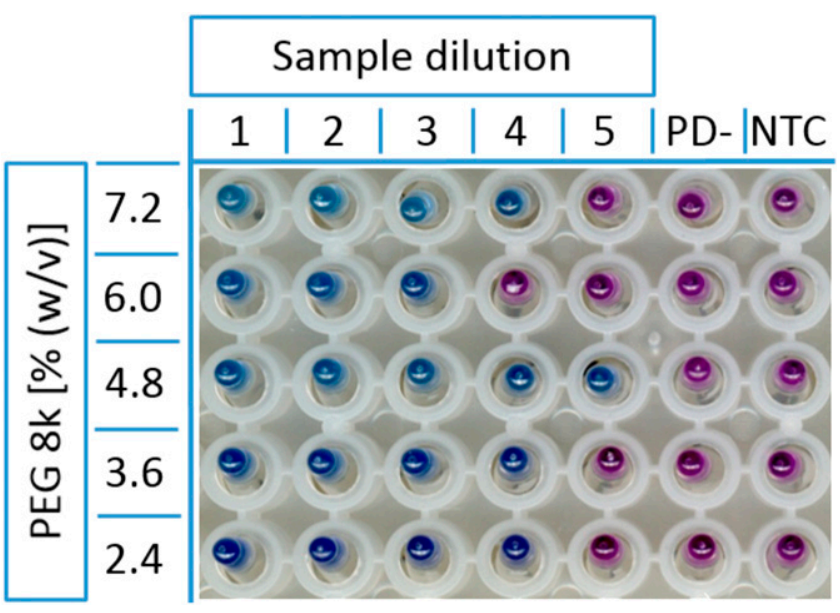

Fig. 3. Pear decline (PD) loop-mediated isothermal amplification analysis applying a polyethylene glycol (PEG) 8k concentration series. The concentration of PEG 8k per reaction (\%) is given on the left. Lanes 1 to $5=$ dilution series of a PD-positive control ( 1 = diluted 1:10, $2=1: 100,3=1: 1,000,4=1: 10,000$, and $5=1: 100,000)$, PD- $=$ PDnegative control, and NTC $=$ no-template control. Eriochromeblack-T was used as the metal indicator dye. 
homogenization of pear tissues was performed in $0.1 \mathrm{M} \mathrm{NaOH}$ and $0.5 \mathrm{M} \mathrm{NaOH}$ for bark and leaves, respectively, instead of distilled water, as reported by Hadersdorfer et al. (2011), because waterbased homogenates of pear leaves strongly inhibited the LAMP reaction (Supplementary Fig. S3). Centrifugation of the homogenates was necessary to separate cell debris from the DNA-containing aqueous solution. The supernatant derived from $\mathrm{NaOH}$-based homogenization of pear tissues was diluted 1:100 in distilled water. In order to evaluate the applicability of crude tissue preparations based on $\mathrm{NaOH}$ to the PD LAMP assay, 30 pear plants that derived from a PD-infected in vitro culture and 10 healthy Williams in vitro pear plants were sampled. The diluted homogenates of the in vitro plants were subjected to PD LAMP with PEG $8 \mathrm{k}$ as well as direct PCR with primers fO1 and rO1. The results were $100 \%$ consistent (Fig. 6). Samples yielding only a faint band in PCR contained enough target DNA to trigger a color change to bright blue in LAMP. No-template controls and samples derived from healthy Williams pear were negative in both assays.

\section{Discussion}

This article reports the development of a LAMP protocol for the detection of the PD phytoplasma. The aim of a laboratoryindependent, easy-to-use detection protocol was achieved with a simplified sample preparation method, a robust DNA amplification assay, and colorimetric visualization of the results.

Sensitivity of LAMP is commonly expected to be almost equal to or higher than that of PCR (Sugawara et al. 2012). The evaluation of the detection limit of the developed PD LAMP assay in comparison with conventional and real-time PCR was conducted with a plasmid containing the target sequence as template (Fig. 4). LAMP was able to detect 100 copies of the target per reaction, being as sensitive as PCR in two of three repetitions when PEG 8k was used as additive in the reaction mix. As expected, real-time PCR was about 100-fold more sensitive than LAMP. The lower sensitivity of LAMP in comparison with real-time PCR is frequently reported for LAMP assays targeting plant pathogens (Harper et al. 2010). Recently, De Jonghe et al. (2017) presented a LAMP assay for the detection of the fruit tree phytoplasmas of the $16 \mathrm{SrX}$ group targeting the $16 \mathrm{~S}$ rRNA gene. The authors reported that the developed LAMP assay was 10-fold less sensitive than a real-time PCR assay for universal phytoplasma detection. A direct comparison of sensitivity of the LAMP assay published by De Jonghe et al. (2017) with that of the PD LAMP assay presented herein is difficult. This is due to the different real-time PCR assays performed for validation as well as the use of a dilution series of a DNA extract derived from an AP-infected apple tree in the sensitivity tests performed by De Jonghe et al. (2017). However, the apparent differences in LAMP assay sensitivities once more underline the observation that primers designed on the same target gene may lead to considerably different performances in LAMP (Sugawara et al. 2012). This phenomenon might be due to secondary structures of the template and the resulting differences in the accessibility of the target.

Because the targeted 16S rRNA gene is present in two copies in the phytoplasma genome (Schneider and Seemüller 1994), the number of phytoplasma cells per gram of sampled plant tissue necessary for a successful detection by the PD LAMP assay (detectable phytoplasma number [DPN]) can be estimated from the determined detection limit using the equation $\mathrm{DPN}=(\mathrm{DL} / \mathrm{CN}) \times(\mathrm{VE} / \mathrm{VL}) \times(1 / \mathrm{SM})$, where DL is the detection limit of the assay (copies of the target), CN is the copy number of the target in the genome, VE is the total volume of the DNA extract, VL is the volume of the DNA extract subjected to LAMP, and SM is the amount of sample material (in grams) from which DNA was extracted. The DNeasy Plant Mini kit (Qiagen), which was used in this study, supports a maximum amount of starting material of $100 \mathrm{mg}$ wet weight. DNA was eluted with $200 \mu \mathrm{l}$ of elution buffer. Based on a detection limit of 100 copies/reaction, the
A

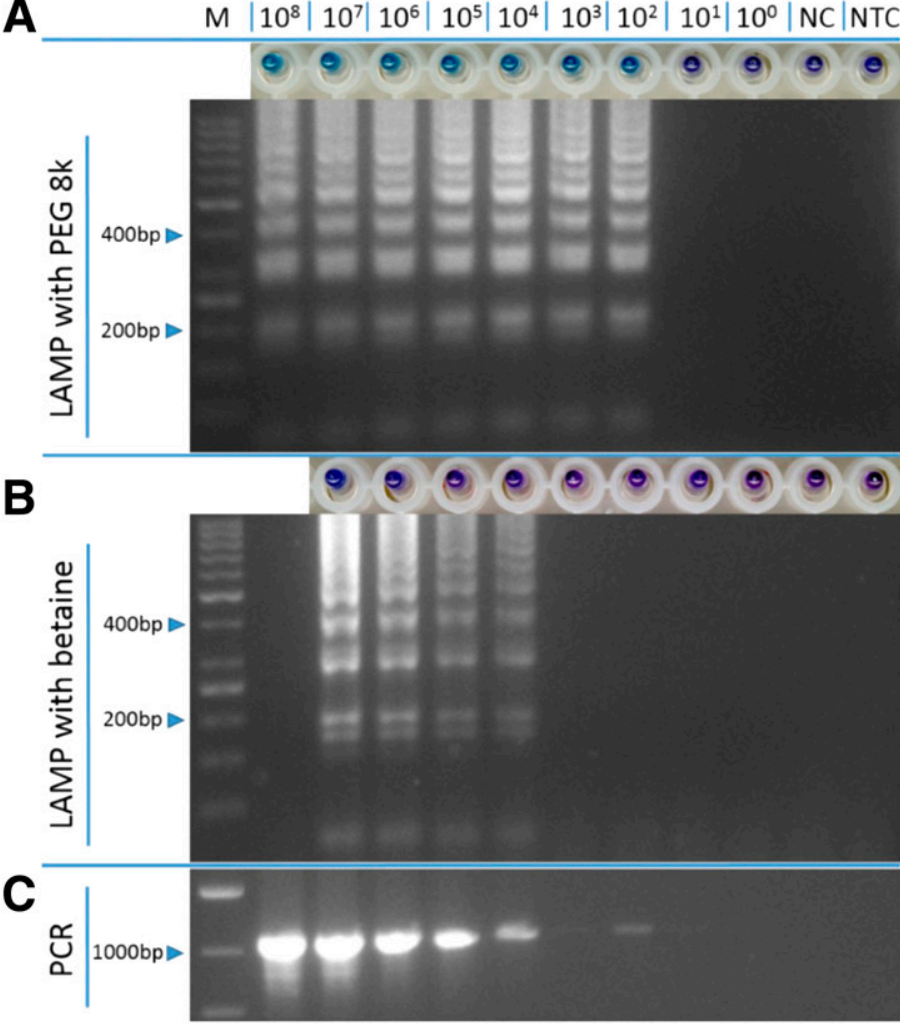

D
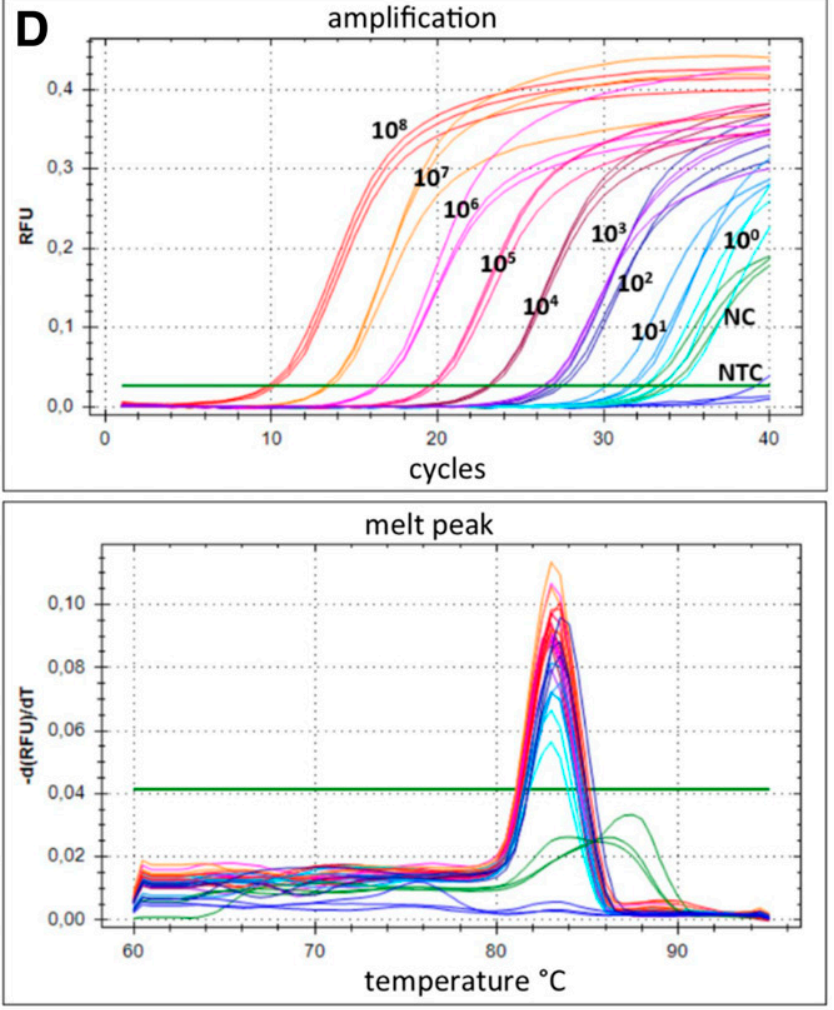

Fig. 4. Detection limit of the pear decline loop-mediated isothermal amplification (LAMP) using a pGemT plasmid containing the P1-P7 fragment of the 'Candidatus Phytoplasma pyri' $16 \mathrm{~S}$ ribosomal DNA sequence with either $\mathbf{A}$, polyethylene glycol (PEG) 8k or B, betaine in comparison with $\mathbf{C}$ conventional polymerase chain reaction (PCR) and D, real-time PCR with SYBR Green I. Copy numbers of the target per LAMP or PCR are given on the left. Lane M = size marker for LAMP GeneRuler 50-bp DNA Ladder (Fermentas) and for PCR GeneRuler 1-kb plus DNA Ladder (Fermentas), NC = negative control, and NTC = no-template control. Real-time PCR amplification curves and melt curve analysis are given on the right. Eriochromeblack-T was used as the metal indicator dye in LAMP reactions. 
calculated DPN according to the equation above is $5 \times 10^{4}$ cells/g of plant tissue. A calculation for the phytoplasma enrichment procedure according to Ahrens and Seemüller (1992) with $0.5 \mathrm{~g}$ of starting material and a final volume of $100 \mu$ yields $5 \times 10^{3}$ phytoplasmas $/ g$ of plant tissue to be detectable by the PD LAMP, when samples were processed with this DNA extraction method. These values are fairly within the range of concentrations reported from fruit tree phytoplasmas. Torres et al. (2005) measured concentrations of $9.7 \times 10^{3}$ to $3 \times$ $10^{5}$ phytoplasmas/g of plant tissue with a real-time PCR assay specific for fruit tree phytoplasmas. Berges et al. (2000) found considerable variation of phytoplasma concentrations in apple trees, in the range of $6.5 \times 10^{2}$ to $1 \times 10^{8}$ cells/g of tissue. Torres et al. (2010) reported an average phytoplasma concentration of $2.3 \times 10^{6}$ cells $/ g$ of plant tissue in 24 pear trees.

In this study, the choice of additive had a strong impact on sensitivity as well as specificity of the developed LAMP assay. Two additives were examined for their influence on assay performance: betaine, which is widely used in LAMP assays, and PEG 8k, which was reported to enhance LAMP assay performance (Denschlag et al. 2013). Betaine is an isostabilizing agent that promotes DNA strand separation by altering its melting characteristics (Jensen et al. 2010). PEG $8 \mathrm{k}$ is a macromolecule that is used to mimic the natural cellular environment, in which 20 to $40 \%$ of the cell volume is occupied by large molecules (Tong et al. 2011). This macromolecular crowding leads to shifts in equilibria and rates of biological reactions, favoring the association of reactants (Minton 2006). When PEG 8k was used as additive in the reaction mix, LAMP was as sensitive as PCR in two of three repetitions. Experiments with different phytoplasma strains to evaluate the detection range of the assay yielded positive results for all tested phytoplasma species (Fig. 5). Subtle differences in the banding patterns compared with the PD-positive

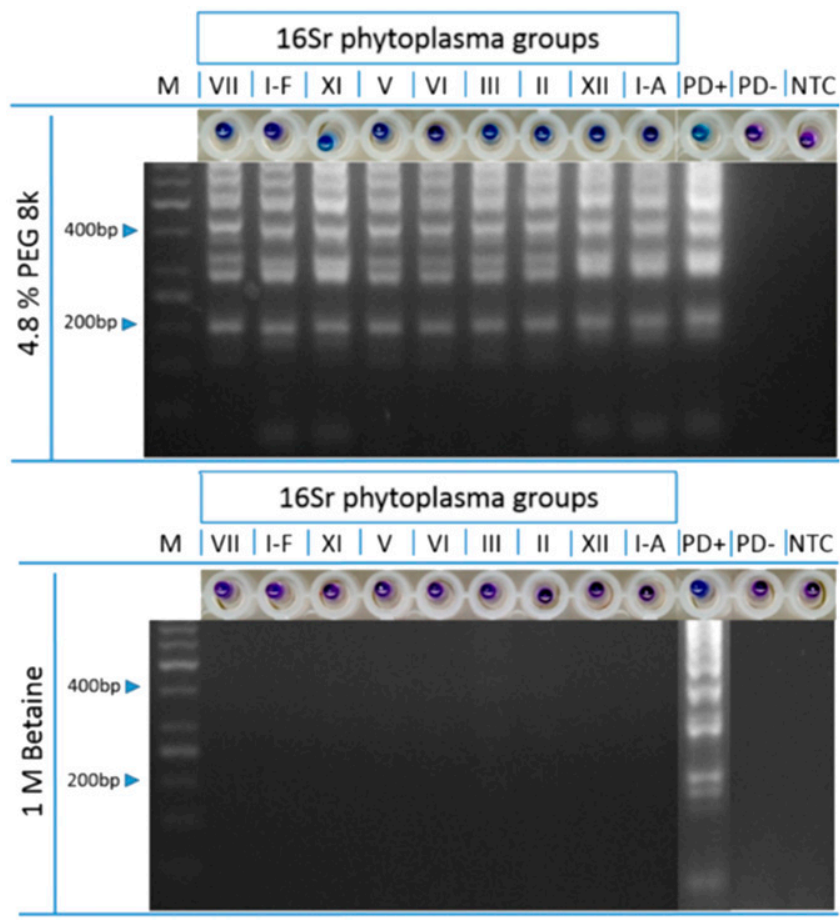

Fig. 5. Detection range of the pear decline (PD) loop-mediated isothermal amplification depending on the applied additive. Visual detection using the metal indicator dye Eriochromeblack-T (top row) and agarose gel electrophoresis of amplicons (bottom row). Tested representatives of the $16 \mathrm{Sr}$ groups: lane $\mathrm{VII}=$ 'Candidatus Phytoplasma fraxini' (ash yellows), I-F = 'Ca. P. asteris' (apricot chlorotic leafroll), $\mathrm{XI}=$ 'Ca. P. oryzae' (flower stunting), V = 'Ca. P. ulmi' (elm witches' broom), $\mathrm{VI}=$ 'Ca. P. trifolii' (potato witches' broom), III = 'Ca. P. pruni' (peach X disease), $I I=$ 'Ca. P. aurantifolia' (tomato big bud), XII = 'Ca. P. solani' (grapevine yellows), $\mathrm{I}-\mathrm{A}=$ 'Ca. P. asteris' (aster yellows), $\mathrm{M}=$ size marker GeneRuler 50-bp DNA Ladder (Fermentas), PD+ = PD-positive control, PD- = PD-negative control, and NTC $=$ no-template control. control were observed on agarose gels, which might be due to altered reaction kinetics because of suboptimal primer binding. When betaine was used instead of PEG 8k, the assay did not yield a color change for any phytoplasma species not belonging to the $16 \mathrm{SrX}$ group. Similarly, Lajin et al. (2013) reported high specificity of a tetra-primer ARMS-PCR assay in the presence of high template DNA concentrations when betaine was used as additive. Tong et al. (2011) presented a study on macromolecular crowding agents and their application for increasing assay performance of HDA. The authors remarked that PEG had the strongest enhancing effects but also led to increased incidence of primer dimer formation in an HDA assay for the detection of Neisseria gonorrheae. Although there was no occurrence of primer dimer formation in the PD LAMP assay, the macromolecular crowding effect of PEG $8 \mathrm{k}$ made it possible to detect a wide range of phytoplasma strains from different phylogenetic groups. Additionally, sensitivity was enhanced by at least one order of magnitude in comparison with the assay with betaine.

Although the PD LAMP assay with betaine was highly specific for phytoplasmas of the 16SrX group, the use of PEG 8k as additive was preferred in this work because it provided the PD LAMP assay with a higher sensitivity. Phytoplasmas having a wide host range such as members of the aster yellows group, which are transmitted by polyphagous vectors, may be occasionally found in pear. Firrao et al. (2005) listed Pyrus communis as a host for ' $\mathrm{Ca}$. P. asteris' (group 16SrI). Lee et al. (1995) reported the detection of mixed phytoplasma infections in symptomatic pear trees. These authors suggested that the combination of phytoplasma infections was responsible for the decline of the trees. Consequently, these mixed infections have to be considered pathogenic and the detection of phytoplasmas in pear, regardless which taxonomic group they belong to, must lead to the classification of the trees as "diseased". Therefore, the use of PEG $8 \mathrm{k}$ as additive in the PD LAMP assay is recommended, accepting the potential detection of phytoplasmas other than the PD phytoplasma in favor of an enhanced assay sensitivity. Tests with field samples covering a range of fruit tree species and cultivars yielded no hints on cross-reactivity with other pathogens or endophytes, because the proportion of positive LAMP results was not conspicuously high (about 42\% across all species and cultivars; Supplementary Table S3). Furthermore, a proportion of the obtained test results was randomly verified with PCR analysis, which showed only minor discrepancies with LAMP results.

High amplification rates in LAMP generate high amounts of the byproduct magnesium pyrophosphate (Mori et al. 2001). Although

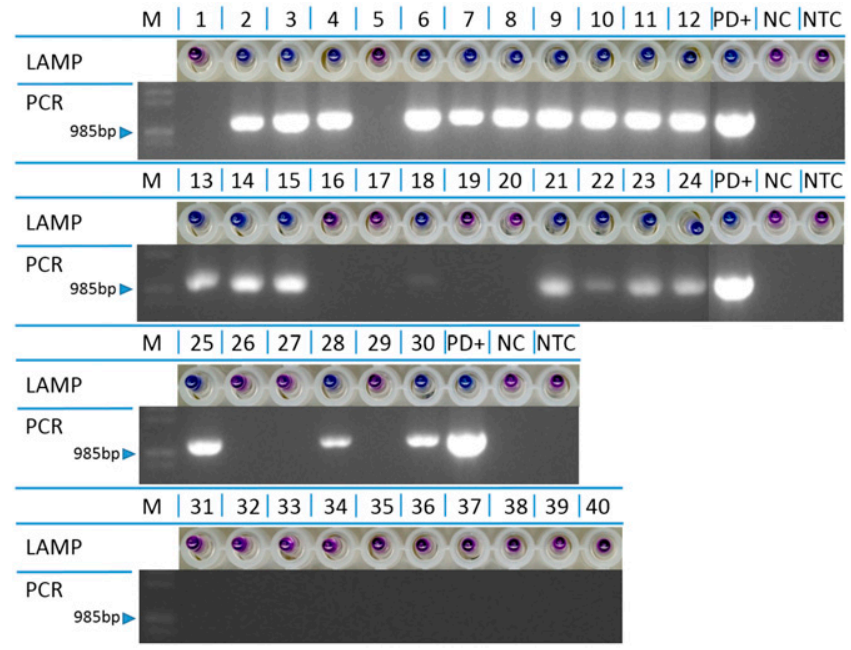

Fig. 6. Comparison of pear decline (PD) loop-mediated isothermal amplification (LAMP) and direct polymerase chain reaction results of $\mathrm{NaOH}$-treated pear samples. Lane $\mathrm{M}=$ size marker $\lambda$ DNA/Eco 471 (Avall) Marker (Fermentas), lanes 1 to $30=$ in vitro pear plants with expected PD infection, lanes 31 to $40=$ healthy in vitro pear plants. PD+ = PD-positive control, PD- = PD-negative control, and NTC $=$ no-template control 
a faint turbidity of the solution due to precipitation of magnesium pyrophosphate is visible to the experienced eye, many approaches use the metal indicator HNB for visualization of LAMP results. HNB indicates decreasing amounts of magnesium ions in the reaction solution by a color change from purple to blue (Goto et al. 2009; Hadersdorfer et al. 2011; Tomlinson et al. 2010). Portable devices that measure turbidity of LAMP reactions in real time are available but costly. Colorimetric detection of LAMP products reduces the technical complexity of the method, enabling an inexpensive application in the field. Soli et al. (2013) evaluated several end-point detection methods for LAMP products and reported that colorimetric detection with HNB or SYBR Green I yielded sensitivities equal to or higher than visual inspection of turbidity or reading with a turbidimeter. However, in our hands, HNB showed varying color intensities and a weak contrast of the color change, which often made a postamplification analysis by agarose gel electrophoresis necessary when PD-positive samples were not distinguishable from negative ones. The search for an alternative dye yielded most promising results for the azo dye ErioT. An experiment comparing the influence of ErioT and HNB on PD LAMP assay sensitivity proved that ErioT had no inhibitory effect on the LAMP reaction in the applied concentration because both assays using either ErioT or HNB showed equal detection limits (Fig. 1). Rodriguez-Manzano et al. (2016) reported that a concentration of $1.4 \mathrm{mM}$ ErioT inhibited the LAMP reaction. However, a concentration of $0.12 \mathrm{mM}$ ErioT per reaction was sufficient to yield strong colors in the PD LAMP assay, which is well below the reported inhibitory concentration. Until now, the use of ErioT in LAMP assays has been only rarely reported (Rodriguez-Manzano et al. 2016; Wang 2014). In this work, ErioT proved to be highly suitable for colorimetric result visualization in the developed PD LAMP assay. The color change in reactions with successful DNA amplification was easily distinguished from the color of solutions with failed amplification reactions (Fig. 1).

The simplified sample preparation procedure presented herein, which uses $\mathrm{NaOH}$ for homogenization of pear tissues, was inspired by Wang et al. (1993), who used $\mathrm{NaOH}$ for a quick extraction of A. thaliana DNA. In a series of experiments, the authors identified alkaline $\mathrm{pH}$ as the most important factor for a simplified sample preparation. Sugawara et al. (2012) also published a simplified extraction method based on alkaline solution. However, the authors incubated the samples in $\mathrm{NaOH}$ at $95^{\circ} \mathrm{C}$, followed by a precipitation step with isopropanol. Although these measures indisputably lead to DNA extracts of higher purity compared with the crude preparations applied in this work, they might not be feasible in the field. Kaneko et al. (2007) demonstrated the high tolerance of LAMP to inhibitory substances in crude sample preparations. Hadersdorfer et al. (2011) reported successful DNA amplification from water-based crude homogenates of plum leaves in a reverse-transcription LAMP assay for the detection of the Plum pox virus. Although this procedure did not work with pear leaves because of LAMP inhibition by the waterbased homogenates, the combination of ideas from Hadersdorfer et al. (2011) and Wang et al. (1993) led to a robust sample preparation method for the application in the PD LAMP as well as direct PCR. Although, in sensitivity tests, conventional PCR was about one order of magnitude more sensitive than LAMP in one of three repetitions, the comparative experiment with crude sample preparations of 30 in vitro pear plants artificially infected with the PD phytoplasma and 10 healthy in vitro pear plants showed clear advantages of the LAMP assay over direct PCR. The results matched $100 \%$ but LAMP was faster with regards to the time required to get results. This demonstrates the suitability of the PD LAMP assay for large-scale screenings in the field. The uneven distribution of phytoplasmas in their hosts makes reliable detection very difficult. Additionally, the amount of PCR inhibiting substances can fluctuate throughout the year. For these reasons, taking more than one sample per plant is recommended (Tomlinson et al. 2010). This considerably raises the costs and time required for DNA extractions, especially in routine screenings. In this context, simplicity and speed of the procedure as well as the lower costs are the most striking advantages of the PD LAMP assay over conventional PCR-based methods.

\section{Acknowledgments}

This work was conducted under the supervision of Prof. Dieter Treutter, who passed away unexpectedly. We thank M. Neumüller for technical advice, A. Bertaccini (University of Bologna, Italy) for kindly providing DNA samples of the phytoplasma strains examined in the evaluation of PD LAMP assay specificity, and B. Schneider (Julius Kühn-Institut, Dossenheim, Germany) for his support and the provision of the plasmid used for the determination of the PD LAMP detection range.

\section{Literature Cited}

Ahrens, U., and Seemüller, E. 1992. Detection of DNA of plant pathogenic mycoplasmalike organisms by a polymerase chain reaction that amplifies a sequence of the $16 \mathrm{~S}$ rRNA gene. Phytopathology 82:828-832.

Berges, R., Rott, M., and Seemüller, E. 2000. Range of phytoplasma concentrations in various plant hosts as determined by competitive polymerase chain reaction. Phytopathology 90:1145-1152.

Betz, J. D., and Noll, C. A. 1950. Total-hardness determination by direct colorimetric titration. J. Am. Water Works Assoc. 42:49-56.

Biedermann, W., and Schwarzenbach, G. 1948. The "complexometric" titration of alkaline earths and some other metals with Eriochromeblack T. Chimia (Aarau) 2:56.

Compton, J. 1991. Nucleic acid sequence-based amplification. Nature 350:91-92.

De Jonghe, K., De Roo, I., and Maes, M. 2017. Fast and sensitive on-site isothermal assay (LAMP) for diagnosis and detection of three fruit tree phytoplasmas. Eur. J. Plant Pathol. 147:749-759.

Deng, S., and Hiruki, D. 1991. Amplification of 16S rRNA genes from culturable and nonculturable mollicutes. J. Microbiol. Methods 14:53-61.

Denschlag, C., Vogel, R. F., and Niessen, L. 2013. Hyd5 gene based analysis of cereals and malt for gushing-inducing Fusarium spp. by real-time LAMP using fluorescence and turbidity measurements. Int. J. Food Microbiol. 162: 245-251.

Fire, A., and Xu, S. 1995. Rolling replication of short DNA circles. Proc. Natl. Acad. Sci. U.S.A. 92:4641-4645.

Firrao, G., Gibb, K., and Streten, C. 2005. Short taxonomic guide to the genus "Candidatus Phytoplasma". J. Plant Pathol. 87:249-263.

Goto, M., Honda, E., Ogura, A., Nomoto, A., and Hanaki, K. I. 2009. Colorimetric detection of loop-mediated isothermal amplification reaction by using hydroxy naphthol blue. Biotechniques 46:167-172.

Hadersdorfer, J., Neumüller, M., Treutter, D., and Fischer, T. 2011. Fast and reliable detection of Plum pox virus in woody host plants using the blue LAMP protocol. Ann. Appl. Biol. 159:456-466.

Harper, S. J., Ward, L. I., and Clover, G. R. G. 2010. Development of LAMP and real-time PCR methods for the rapid detection of Xylella fastidiosa for quarantine and field applications. Phytopathology 100:1282-1288.

IRPCM. 2004. "Candidatus Phytoplasma", a taxon for the wall-less, non-helical prokaryotes that colonize plant phloem and insects. Int. J. Syst. Evol. Microbiol. 54:1243-1255.

Jensen, M. A., Fukushima, M., and Davis, R. W. 2010. DMSO and betaine greatly improve amplification of GC-rich constructs in de novo synthesis. PLoS One 5: e11024.

Kaneko, H., Kawana, T., Fukushima, E., and Suzutani, T. 2007. Tolerance of loopmediated isothermal amplification to a culture medium and biological substances. J. Biochem. Biophys. Methods 70:499-501.

Lajin, B., Alachkar, A., and Sakur, A. A. 2013. Betaine significantly improves multiplex tetra-primer ARMS-PCR methods. Mol. Biotechnol. 54:977-982.

Lee, I. M., Bertaccini, A., Vibio, M., and Gundersen, D. E. 1995. Detection of multiple phytoplasmas in perennial fruit trees with decline symptoms in Italy. Phytopathology 85:728-735.

Lorenz, K. H., Schneider, B., Ahrens, U., and Seemüller, E. 1995. Detection of the apple proliferation and pear decline phytoplasmas by PCR amplification of ribosomal and nonribosomal DNA. Phytopathology 85:771-776.

Minton, A. P. 2006. How can biochemical reactions within cells differ from those in test tubes? J. Cell Sci. 119:2863-2869.

Mori, Y., Kanda, H., and Notomi, T. 2013. Loop-mediated isothermal amplification (LAMP): Recent progress in research and development. J. Infect. Chemother. 19:404-411.

Mori, Y., Nagamine, K., Tomita, N., and Notomi, T. 2001. Detection of loopmediated isothermal amplification reaction by turbidity derived from magnesium pyrophosphate formation. Biochem. Biophys. Res. Commun. 289:150-154.

Notomi, T., Okayama, H., Masubuchi, H., Yonekawa, T., Watanabe, K., Amino, N., and Hase, T. 2000. Loop-mediated isothermal amplification of DNA. Nucleic Acids Res. 28:e63.

Obura, E., Masiga, D., Wachira, F., Gurja, B., and Khan, Z. R. 2011. Detection of phytoplasma by loop-mediated isothermal amplification of DNA (LAMP). J. Microbiol. Methods 84:312-316.

Oh, S. J., Park, B. H., Jung, J. H., Choi, G., Lee, D. C., and Seo, T. S. 2016. Centrifugal loop-mediated isothermal amplification microdevice for rapid, multiplex and colorimetric foodborne pathogen detection. Biosens. Bioelectron. 75:293-300.

Rodriguez-Manzano, J., Karymov, M. A., Begolo, S., Selck, D. A., Zhukov, D. V., Jue, E., and Ismagilov, R. F. 2016. Reading out single-molecule digital RNA 
and DNA isothermal amplification in nanoliter volumes with unmodified camera phones. ACS Nano 10:3102-3113.

Schneider, B., and Seemüller, E. 1994. Presence of two sets of ribosomal genes in phytopathogenic mollicutes. Appl. Environ. Microbiol. 60:3409-3412.

Seemüller, E., and Schneider, B. 2004. 'Candidatus Phytoplasma mali', 'Candidatus Phytoplasma pyri' and 'Candidatus Phytoplasma prunorum', the causal agents of apple proliferation, pear decline and European stone fruit yellows, respectively. Int. J. Syst. Evol. Microbiol. 54:1217-1226.

Seemüller, E., Schneider, B., and Jarausch, B. 2011. Pear decline phytoplasma. Pages 77-84 in: Virus and Virus-like Diseases of Pome and Stone Fruits. A. Hadidi, M. Barba, T. Candresse, and W. Jelkmann, eds. American Phytopathological Society, St. Paul, MN, U.S.A.

Shigemoto, N., Fukuda, S., Takao, S., Shimazu, Y., Tanizawa, Y., Kuwayama, M., and Ohara, S. 2010. Rapid detection of novel influenza A virus and seasonal influenza A (H1N1, H3N2) viruses by reverse transcription-loop-mediated isothermal amplification (RT-LAMP). Kansenshogaku Zasshi [J. Infect.] 84: 431-436.

Skoog, D., West, D., Holler, F. L., and Crouch, S. 2014. Page 431 in: Fundamentals of Analytical Chemistry. Nelson Education, Belmont, CA.

Soli, K. W., Kas, M., Maure, T., Umezaki, M., Morita, A., Siba, P. M., Greenhill, A. R., and Horwood, P. F. 2013. Evaluation of colorimetric detection methods for Shigella, Salmonella, and Vibrio cholerae by loop-mediated isothermal amplification. Diagn. Microbiol. Infect. Dis. 77:321-323.
Sugawara, K., Himeno, M., Keima, T., Kitazawa, Y., Maejima, K., Oshima, K. and Namba, S. 2012. Rapid and reliable detection of phytoplasma by loopmediated isothermal amplification targeting a housekeeping gene. J. Gen Plant Pathol. 78:389-397.

Tomlinson, J. A., Boonham, N., and Dickinson, M. 2010. Development and evaluation of a one-hour DNA extraction and loop-mediated isothermal amplification assay for rapid detection of phytoplasmas. Plant Pathol. 59:465-471.

Tong, Y., Lemieux, B., and Kong, H. 2011. Multiple strategies to improve sensitivity, speed and robustness of isothermal nucleic acid amplification for rapid pathogen detection. BMC Biotechnol. 11:50.

Torres, E., Bertolini, E., Cambra, M., Monton, C., and Martin, M. P. 2005. Real-time PCR for simultaneous and quantitative detection of quarantine phytoplasmas from apple proliferation (16SrX) group. Mol. Cell. Probes 19:334-340.

Torres, E., Laviña, A., Sabaté, J., Bech, J., and Batlle, A. 2010. Evaluation of susceptibility of pear and plum varieties and rootstocks to $\mathrm{Ca}$. P. pyri and Ca. P. prunorum using real-time PCR. Julius-Kühn-Arch. 427:395-398.

Vincent, M., Xu, Y., and Kong, H. 2004. Helicase-dependent isothermal DNA amplification. EMBO Rep. 5:795-800.

Wang, D. G. 2014. Visual detection of Mycobacterium tuberculosis complex with loop-mediated isothermal amplification and eriochrome black T. Appl. Mech. Mater. 618:264-267.

Wang, H., Qi, M., and Cutler, A. J. 1993. A simple method of preparing plant samples for PCR. Nucleic Acids Res. 21:4153-4154. 